\title{
Penerapan Media Musik Irama Melayu Terhadap Minat Siswa Dalam Materi Senam Ritmik Pada Pembelajaran Penjasorkes Siswa Kelas Viii Smp N 1 Kedungwuni
}

\author{
Izzul Ikhsan $^{1 凶}$, Agus Wiyanto $^{2}$, Utvi Hinda Zhanisa $^{3}$
}

Program Studi Pendidikan Jasmani Kesehatan dan Rekreasi, Fakultas Pendidikan

IImu Pengetahuan Sosial dan Keolahragaan, izzulikhsanxiips2@gmail.com

\section{Article Info}

\section{History Articles}

Submitted : 22 Januari 2020

Reviewed : 29 April 2020

Accepted: 18 Juni 2020

\section{Keywords}

Media musik iringan melayu; minat siswa; penjaskorkes; seam ritmik.

\begin{abstract}
Abstrak
Tujuan penelitian ini untuk mengetahui seberapa besar minat siswa kelas VIII dalam pembelajaran senam ritmik dengan menggunakan media musik irama melayu di SMP Negeri 1 Kedungwun. Jenis penelitian ini merupakan penelitian kuantitatif, yang menggunakan disain penelitian quasi experimental design. Populasinya adalah Siswa kelas VIII SMP Negeri 1 Kedungwuni, sampelnya berjumlah 59 siswa yang terdiri dari 28 siswa kelas VIII B dan 31 siswa kelas VIII H. Hasil penelitian ini diperoleh untuk kelas kontrol (VIII H) yang tidak diberikan perlakuan yaitu rata-rata hasil pretest (tes awal) sebesar 67,643 (49,87\%) dan ratarata hasil posttest sebesar $68(50,13 \%)$. Dimana dari data pretest ke posttest untuk kelas kontrol terdapat kenaikan yang kecil yaitu $0,26 \%$. Sedangkan untuk kelas eksperimen yang diberikan perlakuan dengan media musik iringan melayu, diperoleh data hasil pretest (tes awal) sebesar $68,935(48,59 \%)$ dan data hasil posttest (tes akhir) sebesar $72,935(51,41 \%)$. Sehingga terjadi kenaikan minat siswa dari hasil pretest ke posttest sebesar $2,82 \%$. Simpulan dari penelitian adalah, terdapat peningkatan minat pada siswa kelas eksperimen, peningkatan ini terlihat lebih signifikan dibandingkan dengan peningkatan pada kelas control. Saran dari penelitian ini adalah untuk guru penjas diharapkan dapat menerapkan berbagai model pembelajaran yang cocok untuk siswa.
\end{abstract}

\begin{abstract}
The purpose of this study was to determine how much the interest of students in class VIII in rhythmic gymnastics learning using Malay rhythm music media in SMP Negeri 1 Kedungwun. This type of research is a quantitative study, which uses a quasi experimental design research design. The population is students of class VIII of SMP Negeri 1 Kedungwuni, the sample is 59 students consisting of 28 students of class VIII $B$ and 31 students of class VIII $H$. The results of this study were obtained for the control class (VIII H) who were not given treatment ie the average pretest results (initial test) of 67,643 (49.87\%) and the average posttest results were $68(50.13 \%)$. Where from the pretest to posttest data for the control class there was a small increase of $0.26 \%$. As for the experimental class that was given treatment with Malay accompaniment music media, the data obtained from the pretest (initial test) were 68.935 (48.59\%) and the posttest results data (final test) was 72.935 (51.41\%). So that an increase in student interest from the results of the pretest to posttest by $2.82 \%$. The conclusion from the research is, there is an increase in interest in the experimental class students, this increase looks more significant compared to the increase in the control class. Suggestions from this study are for Physical Education teachers are expected to be able to apply various learning models that are suitable for students
\end{abstract}

Alamat korespondensi :

Alamat : Gedung Pusat Lt.3 Universitas PGRI Semarang 


\section{PENDAHULUAN}

Pendidikan jasmani adalah proses pendidikan yang memanfaatkan aktivitas jasmani yang direncanakan secara sistematik. Pendidikan jasmani menilai seluruh aspek yang ada mulai dari aspek kognitif, afektif, dan psikomotor. Pendidikan jasmani merupakan upaya agar dapat mengaktualisasikan seluruh potensi aktivitasnya sebagai manusia berupa sikap, tindakan dan karya yang diberi bentuk, isi dan arah menuju kebulatan pribadi sesuai cita - cita kemanusiaan (Rochdi dan Yudha, 2007:5)Kedudukan mata pelajaran Pendidikan Jasmani, Olahraga dan Kesehatan (Penjasorkes) di dalam kurikulum pendidikan sangatlah penting. Karena mata pelajaran ini digunakan sebagai salah satu kelompok bidang studi penting yang harus diajarkan sejak sekolah dasar sampai sekolah menengah pertama. Peraturan Pemerintah Nomer 19 Tahun 2005 tentang Standart Nasional Pendidikan pasal 6 ayat (1) menyatakan bahwa kurikulum untuk jenis pendidikan umum, kejuruan dan khusus pada jenjang pendidikan dasar dan menengah salah satu diantaranya adalah kelompok mata pelajaran Pendidikan Jasmani, Olahraga dan Kesehatan.

Aktivitas ritmik adalah bagian dari senam atau senam irama, dengan kategori gerak stabilisasi dan manipulasi dari berbagai gerakan alat bersamaan dengan tubuh. Sedangkan senam ritmik merupakan senam yang dilakukan untuk menyalurkan rasa seni atau keindahan untuk membina serta meningkatkan seni gerak. Secara umum, senam ritmik tidak berbeda dengan senam yang biasa dilakukan. Hanya saja, pada senam irama ditambahkan irama (ritme). Tekanan yang harus diberikan pada senam ritmik ialah irama, kelentukan, dan kontuinitas gerakan (Muhajir, 2007). Dilihat dari hakikat karakteristik dan struktur geraknya, senam merupakan kegiatan fisik yang sesuai digunakan untuk mengkembangkan kualitas motorik dan kualitas fisik. Hal tersebut dapat dilihat dalam kandungan gerak lokomotor yang dianggap mampu meningkatkan aspek kekuatan, kecepatan, power, daya tahan, keseimbangan, kelincahan dinamis (Rutkauskaite, $2005: 51$ ).

Senam ritmik menurut Lia dan Agung (2016: 169) adalah senam yang sering disebut senam irama. Senam ritmik merupakan senam yang memiliki gerakan bebas dengan menciptakan keserasian berirama. Senam irama atau senam ritmik berasal dari pengembangan senam yang bertujuan menyalurkan hasrat untuk bergerak. Senam ritmik terdiri dari gerakangerakan yang tidak boleh terputus. Dalam melakukan setiap gerakan senam ritmik, perlu adanya kelenturan, keluwessan, keseimbangan, dan fleksibilitas.

Musik adalah bagian dari seni yang menggunakan bunyi sebagai media penciptaannya. Walaupun dari waktu ke waktu beraneka ragam bunyi, seperti klakson maupun mesin sepeda motor dan mobil, handphone, radio, televisi, tape recorder, dan sebagainya senantiasa mengerumuni kita, tidak semuanya dapat dianggap sebagai musik karena sebuah karya musik harus memenuhi syarat-syarat tertentu. Syarat-syarat tersebut merupakan suatu sistem yang ditopang oleh berbagai kompnen seperti melodi, harmoni, ritme, timbre (warna suara), tempo, dinamika, dan bentuk (Moh. Muttaqin, 2008: 3).

Di Indonesia terdapat aliran musik yang khas yaitu musik dangdut. Menurut Rachmad (2011: 5) musik dangdut merupakan hasil perpaduan antara musik india dengan musik musik melayu, musik ini kemudian berkembang dan menampilkan cirinya yang khas dan berbeda dengan musik akarnya. Ciri khas musik ini terletak pada pukulan alat musik tabla (sejenis 
alat musik perkusi yang menghasilkan bunyi ndut). Selain itu, iramanya ringan, sehingga mendorong penyanyi dan pendengarnya untuk menggerakan anggota badannya. Menurut Slamet Haryono (2002: 25) musik dangdut juga disebut 'pop melayu', adalah jenis musik yang pada awalnya muncul dengan dasar irama melayu yang kemudian terpengaruh oleh nada dan beat irama hindustan.

Muhammad Takari (2001: 55) dalam definisinya menyatakan bahwa dangdut adalah satu ragam seni musik nusantara yang berasal dari seni etnis melayu, di dalamnya mengandung unsur-unsur musik India, Arab dan Melayu. Musik ini kemudian berkembang dengan mengadopsi unsur-unsur musik barat.

Dangdut merupakan musik yang akrab dengan lingkungan masyarakatnya. Apabila kita amati pertunjukan musik dangdut memiliki ciri khas yang istimewa dan cair sifatnya. Kita dapat menengok misalnya bagaimana dangdut bergerak dalam ruang dan pembatas yang diberikan oleh globalisasi. Musik dangdut diterima masyarakat sebagai salah satu musik yang populer di indonesia bersanding dengan yang lainnya (Simatupang, 2000: 10)

Hasil wawancara dengan guru penjas di beberapa sekolah pada 26 Maret 2019 menyimpulkan bahwa rata - rata pada pembelajaran penjasorkes materi senam irama sudah menggunakan media musik, tetapi yang menggunakan media musik dangdut hanya di sekolah MTS YMI Wonopringgo dan SMP 2 Kedungwuni.

Dari fenomena yang ada di SMP Negeri 1 Kedungwuni peneliti ingin mengetahui seberapa besar minat siswa dalam pembelajaran penjasorkes materi senam ritmik yang dilakukan dengan media musik. Karena keterbatasan kami, peneliti hanya akan mengambil siswa kelas VIII untuk dijadikan sampel yang ada di SMP Negeri
1 Kedungwuni, sedangkan materi yang akan diambil adalah materi senam irama. Karena pada saat peneliti melihat situasi di lapangan minat siswa ketika pembelajaran senam irama tanpa menggunakan media musik itu kurang, banyak yang lemas ketika pembelajaran, dan juga dengan media musik barat masih sama saja dibandingkan dengan ketika menggunakan musik dangdut waktu acara senam satu sekolahan semua siswa bersemangat bergerak ketika mendengar alunan musik dangdut. Dan disini peniliti akan coba melakukan pembelajaran penjasorkes pada materi senam irama dengan menggunakan media musik irama melayu (dangdut) untuk mengetahui seberapa besar minat siswa ketika pembelajaran senam ritmik.

Berdasarkan hasil pengamatan dan uraian latar belakang tersebut penulis tertarik untuk meneliti lebih dalam tentang "Penerapan Media Musik Irama Melayu Terhadap Minat Siswa Dalam Materi Senam Ritmik Pada Pembelajaran Penjasorkes Siswa Kelas VIII SMP N 1 Kedungwuni"..

\section{METODE}

Jenis penelitian ini merupakan penelitian kuantitatif, yang menggunakan desain penelitian Quasi Experimental Design. Ada beberapa desain penelitian eksperimen, dalam penelitian ini digunakan Quasi Experimental Design (Sugiyono, 2018: 120). Desain ini memiliki kelompok kontrol, tetapi tidak dapat berfingsi sepenuhnya untuk mengontrol variable-variabel luar yang mempengaruhi pelaksanaan eksperimen. Dalam Quasi Experimental Design terdapat dua bentuk desain quasi eksperimen, yaitu Time-Series Design dan Nonequivalent Control Group Design.

Desain yang digunakan dalam penelitian ini adalah Nonequivalent Control Group Design 
(Sugiyono, 2018:122) pada desain eksperimen ini terdapat kelas eksperimen dan kelas kontrol sebagai pembanding. Pada penelitian ini, peneliti memberi perlakuan khusus menggunakan media music irama melayu (dangdut) dalam pembelajaran penjasorkes materi senam ritmik pada kelas eksperimen.

Populasi dalam penelitian ini adalah siswa kelas VIII SMP N 1 Kedungwuni Kabupaten Pekalongan. Untuk menentukan sampel yang akan digunakan dalam penelitian. Teknik penarikan sampel dalam penelitian ini menggunakan sampling purposive. Pemilihan sampel ini dikarenakan pertimbangan jadwal pelajaran PJOK di hari yang sama, agar memudahkan dalam penelitian. Sampel dalam penelitian ini adalah 2 kelas, yaitu VIII B sebagai kelas experimen dan kelas VIII H sebagai kelas control.

Dalam penelitian ini terdapat variable bebas dan terikat. Variabel bebasnya adalah Penerapan Media Musik Irama Melayu dan variabel terikatnya adalah Minat Siswa Dalam Pembelajaran Penjasorkes Dalam Materi Senam Ritmik.

Teknik pengumpulan data pada penelitian ini yakni Wawancara, Observasi, Uji validitas untuk 20 item pertanyaan pada hasil minat siswa terhadap pembelajaran senam irama di SMP Negeri 1 Kedungwuni. Item angket dalam uji validitas dikatakan valid jika rhitung $>$ rtabel atau nilai Sig. $<\alpha=0,05$ pada signifikansi $5 \%$. Uji reliabilitas dengan Cronbach's Alpha dan diketahui bahwa nilai Cronbach's Alpha sebesar 0,772. Karena nilai Cronbach's Alpha lebih besar dari 0,7. Maka dapat dikatakan bahwa item-item pertanyaan pada angket tersebut reliabel diketahui bahwa nilai Cronbach's Alpha sebesar 0,772 . Karena nilai Cronbach's Alpha lebih besar dari 0,7. Maka dapat dikatakan bahwa item-item pertanyaan pada angket tersebut reliabel. Teknik analaisis data menggunakan data statistic inferensial.

\section{HASIL DAN PEMBAHASAN}

\section{Deskripsi umum Subjek Penelitian}

Penelitian ini dilakukan di SMP Negeri 1 Kedungwuni, Kecamatan Kedungwuni Kabupaten Pekalongan Provinsi Jawa Tengah pada pembelajaran penjasorkes khususnya pada materi senam irama yang bertujuan untuk mengetahui peningkatan minat siswa dalam pembelajaran penjasorkes pada materi senam irama dengan menerapkan media musik dangdut. Dimana sampel penelitian yaitu kelas VIII dengan kelas kontrol yaitu kelas VIII H sebanyak 28 siswa dan kelas eksperimen yaitu kelas VIII B sebanyak 31 siswa. Penelitian dilaksanakan tanggal 4 dan 11 September 2019 . Penelitian dilakukan dengan memberikan angket yang terdiri dari 14 butir pertanyaan kepada para siswa pada saat tes awal (pretest) dan saat tes akhir (posttest) dengan kelas kontrol (VIII H) yang tidak diberikan perlakuan dan kelas eksperimen (VIII B) yang diberikan perlakuan dengan media musik irama melayu (dangdut).

\section{Persentase Peningkatan Minat Siswa} Terhadap Pembelajaran Senam Ritmik Untuk Kelas Kontrol dan Kelas Eksperimen

Tabel 4.11 Hasil Uji Hipotesis untuk Kelas Kontrol dan kelas Eksperimen

\begin{tabular}{ccccc}
\hline Kelas & Data & $\begin{array}{c}\text { Rata- } \\
\text { rata }\end{array}$ & $\begin{array}{c}\text { Persenta } \\
\text { se\% }\end{array}$ & $\begin{array}{c}\text { Peningkat } \\
\text { an\% }\end{array}$ \\
\hline $\begin{array}{c}\text { Kelas } \\
\text { kontrol } \\
\text { VIII H }\end{array}$ & Pretes & $\begin{array}{c}67,64 \\
3\end{array}$ & $49,87 \%$ & \\
& Postes & 68 & & $0,26 \%$ \\
Total & & $\begin{array}{c}135,6 \\
43\end{array}$ & $100 \%$ & \\
\hline
\end{tabular}




\begin{tabular}{ccccc}
\hline Kelas & Data & Rata-rata & $\begin{array}{c}\text { Persent } \\
\text { ase } \%\end{array}$ & $\begin{array}{c}\text { Peningk } \\
\text { atan\% }\end{array}$ \\
\hline $\begin{array}{c}\text { Kelas } \\
\text { eksperim }\end{array}$ & Pretes & 68,935 & $48,59 \%$ & \\
en VIII B & Postes & 72,935 & $51,41 \%$ & $2,82 \%$ \\
& & 141,871 & $100 \%$ & \\
Total & & & & \\
\hline Sumber : Data primer yang diolah, 2019
\end{tabular}

Berdasarkan hasil perhitungan diatas, diperoler eksperimen yang diberikan perlakuan dengan media musik dangdut, diperoleh data hasil pretest (tes awal) sebesar 68,935 (48,59\%) dan data hasil posttest (tes akhir) sebesar 72,935 $(51,41 \%)$. Sehingga terjadi kenaikan minat siswa dari hasil pretest ke posttest sebesar $2,82 \%$. Oleh karena itu dapat disimpulkan bahwa terdapat pengaruh pemberian media musik iringan melayu terhadap peningkatan minat siswa terhadap pembelajaran senam ritmik kelas VIII di SMP 1 Kedungwuni dengan besar peningkatannya yaitu $2,82 \%$.

\section{Pembahasan}

Penelitian ini diadakan untuk mengetahui minat siswa dalam materi senam ritmik dengan menggunakan media musik iringan melayu (dangdut) siswa kelas VIII SMP Negeri 1 Kedungwuni. Penelitian dilaksanakan pada tanggal 4 dan 11 September 2019. Dalam pelaksanaannya diadakan tes awal pengisian angket, untuk mengetahui kondisi awal minat siswa. Kemudian saat pembelajaran dilakukan observasi sikap siswa, pada akhir penelitian atau setelah materi diadakan test pengisian angket kedua untuk mengetahui ada atau tidaknya perubahan minat pada siswa.

Kelas kontrol (VIII H) yang tidak diberikan perlakuan memiliki rata-rata hasil pretest (tes awal) sebesar $67,643(49,87 \%)$ dan rata-rata hasil posttest sebesar $68(50,13 \%)$. Dimana dari data pretest ke posttest untuk kelas kontrol terdapat kenaikan yang kecil yaitu $0,26 \%$.
Sedangkan untuk kelas eksperimen yang diberikan perlakuan dengan media musik dangdut, diperoleh data hasil pretest (tes awal) sebesar 68,935 (48,59\%) dan data hasil posttest (tes akhir) sebesar 72,935 (51,41\%). Sehingga terjadi kenaikan minat siswa dari hasil pretest ke posttest sebesar $2,82 \%$. Oleh karena itu dapat


media musik irama melayu terhadap peningkatan minat siswa terhadap pembelajaran senam ritmik kelas VIII di SMP 1 Kedungwuni dengan besar peningkatannya yaitu 2,82\%. Sehingga pemberian media musik irama melayu efektif meningkatkan minat siswa terhadap pembelajaran senam ritmik.

\section{KESIMPULAN DAN REKOMENDASI}

Berdasarkan hasil penelitian, minat siswa terhadap materi senam irama yang menggunakan media musik dangdut diperoleh untuk kelas kontrol (VIII H) yang tidak diberikan perlakuan yaitu rata-rata hasil pretest (tes awal) sebesar $67,643(49,87 \%)$ dan rata-rata hasil posttest sebesar $68(50,13 \%)$. Dimana dari data pretest ke posttest untuk kelas kontrol terdapat kenaikan yang kecil yaitu $0,26 \%$. Sedangkan untuk kelas eksperimen (VIII B) yang diberikan perlakuan dengan media musik irama melayu, diperoleh data hasil pretest (tes awal) sebesar $68,935(48,59 \%)$ dan data hasil posttest (tes akhir) sebesar 72,935 (51,41\%). Sehingga terjadi kenaikan minat siswa dari hasil pretest ke posttest sebesar $2,82 \%$. Oleh karena itu dapat disimpulkan bahwa terdapat pengaruh pemberian media musik dangdut terhadap peningkatan minat siswa terhadap pembelajaran senam irama kelas VIII di SMP 1 Kedungwuni dengan besar peningkatannya yaitu $2,82 \%$.

Dengan mengacu pada hasil penelitian dan keterbatasan peneliti, peneliti menyarankan: 
1. Pendidik maupun calon pendidik bisa lebih tegas pada siswa, dan lebih bisa mengerti siswa.

2. Bagi guru penjas, diharapkan dapat menerapkan berbagai model pembelajaran yang cocok untuk siswa, saat melakukan pembelajaran

\section{DAFTAR PUSTAKA}

Agung dan Lia. (2016). Pendidikan Jasmani Olahraga dan Kesehatan SMA/MA/SMK Kelas XI. Surakarta: Mediatama

Haryono, S. (2002). "Dangdut dan Eksploitasi Seks Perempuan". Jurnal Pengetahuan dan Pemikiran Seni. 3 (2) 8-9. (https://journal.unnes.ac.id diakses 20 November 2019)

Muhajir. (2007). Pendidikan Jasmani Olahraga dan Kesehatan. Bandung: Erlangga.

Muhammad, S. (2017). Pengaruh Minat Belajar Penjas Siswa Terhadap Tingkat Kesegaran Jasmani Siswa Kelas Tinggi Kategori Putra SD Hj. Isriati Moenadi Kecamatan Ungaran Timur Kabupaten Semarang Tahun Pelajaran 2016/2017. Skripsi. Semarang: PJKR Universitas Wahid Hasyim.

Muttaqin Kustap, M. (2008). Seni Musik Klasik Jilid I Untuk SMK. Jakarta: Direktorat Pembinaan Sekolah Menengah Kejuruan, Direktorat Jenderal Manajemen Pendidikan Dasar dan Menengah, Departemen Nasional.

Rachmad. (2011). Pengertian Dangdut. Bandung: Erlangga

Rutkauskaite, R. (2005). "The interaction of training and sport performance in rhythmic gymnastics during competion periode". Education Physical Training Sport. 4 (8): 49 55 (https://journal.unnes.ac.id diakses 21 November 2019)
Sudijono. (2012). Pengantar Evaluasi Pendidikan. Jakarta: Raja Grafindo Persada. Sudrajat, A. (2008). Pengertian, Fungsi, dan Mekanisme Penetapan KKM. Jakarta: Raja Grafindo

Sugiman. dkk. (2016). Karakteristik Siswa SMP. Jakarta: Direktorat Jenderal Guru dan Tenaga Kependidikan

Sugiyono. (2011). Metode Penelitian Pendidikan. Bandung: Alfabeta.

Sugiyono. (2013). Skripsi, Tesis, dan Disertasi. Bandung: Alfabeta.

Sugiyono. (2016). Metode Penelitian Pendidikan. Bandung: Alfabeta.

Sugiyono. (2018). Metode Penelitian Kuantitatif. Bandung: Alfabeta.

Suryabrata, Sumadi. (2014). Psikologi Pendidikan. Jakarta: Rajagrafindo Persada Takari, M. (2001). "Akulturasi Kebudayaan Musikal Dalam Seni Pertunjukan Dangdut". Jurnal Masyarakat Etnomusikologi $\begin{array}{llll}\text { Indonesia. } & 1 & \text { (1) } & 103 .\end{array}$ (https://www.etnomusikologiusu.com diakses 20 November 2019)

Usman, Moh. Uzer. (2010). Menjadi Guru Profesional. Bandung: Remaja Rosdakarya. Walgito, Bimo. (2010). Pengantar Psikolog Umum. Yogyakarta: C.V Andi. Offset

Wicaksono, I. (2011). Penggunaan Musik Sebagai Media Pembelajaran di Taman Kanak - Kanak Hj. Isriati Baiturrahman 1 Semarang. Skirpsi. Semarang: Sendratasik UNNES 